\title{
Priority Areas Of Spiritual, Moral And Physical Education Of Youth In The Family
}

\author{
Narbaeva T.K. , Uzbek State World Languages University, Republic of Uzbekistan \\ Musurmanova A., Uzbek State World Languages University, Republic of Uzbekistan
}

\begin{abstract}
This article is devoted to strengthening the institution of the family in Uzbekistan. From the scientific and pedagogical point of view, the state policy implemented in this area, its priority areas, the nature and content of the institution of the family are revealed. Also, the authors propose pedagogical principles, innovative forms, methods and means of spiritual, moral and physical education of youth in the family, developed conclusions and recommendations on this issue.
\end{abstract}

Keywords: family institution, priority areas, legal and regulatory documents, spiritual, moral and physically developed generation, pedagogical principles, innovative forms, methods and means of education, pedagogical diagnostics, pedagogical mechanisms.

Received: 07.12.2020 $\quad$ Accepted: 10.01.2021 $\quad$ Published: 03.02.2021

\section{Introduction}

In Uzbekistan, the dynamic changes are taking place in public, social and economic life, which contributes to the transformation and institution of the family, which is inseparable sub-system of the country, which is able to successfully address the specific function of reproduction and socialization of new generations. As a social institution, the family is major component of the society. Therefore, when the serious changes taking place in the society, the importance of the study of the family as a social system is increased. And also, study the relationships between family and state, conceptual and substantive basis of the state family policy in a multi-ethnic, multicultural environment of Uzbekistan increased.

In easten countries, the family is the solid foundation of society, which has evolved over the centuries, as well as its great dynamic power. And its social and spiritual development is the foundation of the welfare state and society. Therefore, from the very first days of independence, Uzbekistan's support for women and strengthening the institution of family - has become one of the priority issues of social policy. "First of all, in order to protect mothers and children, strengthen the family as the basis for developing a stable state has been strengthened legislative and regulatory framework" - said the President of the Republic of Uzbekistan Sh.M.Mirziyoev.

In all civilizations, family has been one of the most important components of global development. The ideology of the priority of the family institution, its value to human life and development as a whole, the younger generation and society in particular, is fixed in many international and national level regulations. In particular, the methodological basis for strengthening and stabilizing the institution of the family is such regulatory documents as the "Family Code" of the Republic of Uzbekistan (1998), the Laws of the Republic of Uzbekistan "On additional benefits for women" (1999), "On guarantees of the rights of the child" (2008) , "On family business" (2012), "On protecting women from oppression and violence” (2019) and "On guarantees of equal rights and opportunities for women and men" (2019), Resolution of the President of the Republic of Uzbekistan PF-5325 "On measures to radical improvement measures in the area of supporting women and strengthening the institution of the family " (2018), Cabinet of Ministers Resolution No.175 of June 19, 2012 "On measures to further strengthen the interaction of the family institution and self-government bodies of citizens with educational institutions in the education of a harmoniously developed generation", as well as the Convention No. 103 of the International Labor Organization "On the Protection of Maternity" (1952), Convention No. 156 "On Equal Treatment and Equal Opportunities for Workers of Men and Women: Workers with Family Responsibilities" (1981) and others. The measures taken to ensure the implementation of these regulatory documents, in particular, the announcement by the President of the Republic of Uzbekistan of the "Year of the Family" (1998), "The Year of Women" (1999), "The Year of the Healthy Generation" (2000), "The Year of Mother and child" (2001), "The Year of the mahalla" (2003), "The Year of a strong family" (2012) and in this regard, state programs adopted by the Cabinet of Ministers of the Republic of Uzbekistan, the Concept "Cooperation of the family, mahalla and educational institutions" (2012), and also, ratification of a number of international conventions aimed at the protection of the legal interests of the family, motherhood and 
childhood (ILO 103 (1952), 156 (1981)) play an important role in fundamentally improving efforts to strengthen family institutions based on national and international laws.

We know that in the evolution of human society, there are different approaches to solving the problems relating to the family institution. As a result, in the developed countries there has been formed the most rational approach to solving this problem, that is, the creation of the classic family unit of a modern society based on religious and national-ethnic characteristics of each nation. But, of course, we cannot assert that this approach is completely well formed, i.e. each stage of human development makes corrections in each stage of social life. Through a lot of trial and error, humanity continues to move forward in its development, and it is difficult to state categorically what is right, and what is wrong. That is why the research of the family institutions is one of the most actual topics in all countries of the world, including in our country, since it is one of the most important and significant subsystems of the state and society.

Based on the relevance of the problem in the research process, the place and role of family institutions in the implementation of the specific function of socialization and upbringing of the young generation were disclosed, the scientific and methodological aspects of the essence and content of the upbringing of a spiritually-physically harmoniously developed generation in our country were considered, priority areas for ensuring a strong family were identified, ensuring continous and continuity, as well as pedagogical cooperation in improving the effectiveness of work in the field of protection of the family, motherhood childhood.

\section{Priority areas to ensure family stability, spiritual, moral and physical upbringing of young generation in the family}

The most basic task of a family is to give birth to a child, to procreate, to ensure the continuity of the nation, to educate young people as worthy people of society. Other family tasks are based on the education of young generation. Indeed, in the field of strengthening the family and promoting peace and harmony, durability, social and economic stability in stages, step by step taken important steps.

As it is known, in accordance with the Strategy of Action for the five priority areas of the Republic of Uzbekistan for 2017-2021 years in the spiritual and moral and physical education of youth in a number of educational institutions with the most important tool is the family. Indeed, in today's fast paced time, "The most important condition for sustainable and dynamic development of the country is the harmoniously enriched education".

Therefore, Uzbekistan has a solid legal basis for the social support of the family, motherhood and childhood, that is, the family as a small community to be a comprehensive legal protection in society.

The Constitution of the Republic of Uzbekistan stated "The family has the right to the State and society protection " (Article 63), "Motherhood and childhood are protected by the state" (Article 65), "Parents are obliged to support and care for their children until the age of maturity" (Article 64) "Mature and ablebodied children are obliged to care for their parents" (article 66). The legal basis for strengthening the institution of family is also reflected in the "Family Code" of the Republic of Uzbekistan (1998), the Law "On establishment of family business" (2012) and a number of other laws.

In this regard, from the first days of independence of our country work on promotion and integration into society of the constitutional principle of "family under the protection of society and the state" is based on the following priority areas:

- to strengthen the institution of the family, first of all, it is necessary to further improve the regulatory framework to implement the concept of "Healthy family - healthy society";

- providing affordable and comfortable accommodation with favorable conditions for women caught in difficult social situation, as well as mothers raising children in single-parent families and in need of better housing conditions and providing them with the necessary privileges and advantages;

- the attention of all the institutions in a society geared to ensuring the ssustainability of the family, strengthen their impact on family support;

- according to the principle of "Healthy mother - healthy child" to ensure reproductive health and demographic development of the family, its well-being and tranquility, the formation of the family a healthy lifestyle;

- further development of the spiritual foundations of the family, based on the preservation and strengthening of its ancient values to achieve spiritual perfection of society. Establishing a family spiritual climate, increased space and family values in opposition to various harmful influences that are completely alien to our mentality;

- strengthening the role of the family in the education of physically healthy, spiritually mature and harmoniously developed generation, to this end, the strengthening of the mechanism of interaction and 
unity of the family and civil society institutions with training and educational institutions, ensuring their close and effective, consistent, and continuous practical cooperation;

- the development of a modern family, hold a fundamental, practical and innovative research on internal relations of the family, interpersonal relationships, rich cultural and historical heritage and traditional family values, based on them to strengthen the family institution, preparation of youth for family life and the prevention of family divorce.

In consequence of the scientific analysis of existing material has been revealed that in recent years in our country with regard to increasing the socio-political and social activity of women, creation of conditions for the implementation of their skills and abilities in various fields and industries, to ensure unconditional observance of the rights and legitimate interests of women, comprehensive support of maternity and childhood, upbringing harmoniously developed generation, as well as the strengthening of the family institution has been done a number of important action and has been achieved quite a few positive results.

\section{Improving teacher training mechanisms spiritual, moral and physical development of the individual}

Everyone knows that the family has a great influence on the formation and development of the personality. Family education largely determines the system of human needs and motivations, his perception of the world, self-esteem and adaptive capacity. To a large extent it is under the influence of family education are laid and formed spiritual, moral, cultural and aesthetic ideas of the younger generation. Therefore, the question of the goals and values of educating the younger generation in any society and in any period of human development is one of the most important, and the answer to it largely determines the future of society itself.

As we mentioned above, at the basis of all measures taken to strengthen the institution of the family, first of all lies such an important goal as the formation of a spiritual, moral, physically developed personality. The content of the spiritual, moral and physical education of youth in the family is large-scale, which is essential, parents, teachers and the general public have to have clear and comprehensive understanding of the meaning of this concept. Morality - "Historically human behavior, relationships in social and personal life, as well as a set of stable, certain rules and regulations governing the relationship to society" [13. C 48]. External criterion of morality is "the fulfillment of the views and demands of society", the internal criterion is the "conscience" [14.S.429]. A spirituality - is "the eternal human desire for universal values: truth, beauty, goodness." [14.S.189]. Just "spiritual education - is a means of education of high spirituality, it is a concept that is of practical educational process aimed at the formation of such qualities as physical perfection, mental, moral, spiritual human maturity in the team, in a particular group in society, in the nation [13.317-318 C].

According to research the concept of spiritual and moral education includes the following: compliance with the rules of everyday life, in any situation, keep yourself in hand, modesty, patience, cleanliness, neatness, thoughtfully, to speak as part of etiquette, to be free from all kinds of immorality, faith, conscious discipline, have a sense of national pride, to follow the rules of behavior and healthy lifestyles (clothing, food, personal hygiene, to maintain physical health), the culture of communication, love of the National and family values, following the economic culture, to respect their elders and to be attentive to the younger, show love for literature and art, respect for the customs and traditions, language, religion and culture of various ethnic groups, tolerance, patience, labor, culture and others [16 15.s ]. Thus, in our opinion, the goal of spiritual and moral education is the conscious manifestation of universal and national rules of behavior adopted by mankind in the daily and practical activities of a person through his actions and behavior.

Pupils and students who study in educational institutions are born and brought up in a spiritually healthy environment or not healthy; complete or incomplete; in need of protection; low-income, breadwinner; different nationalities and religious faiths with different social status; intelligent, workingentrepreneurial and in other families. Therefore, the educational work carried out on the basis of the pedagogy of cooperation is organized taking into account the categories of educational institutions and students. In view of the foregoing, in organizing thematic educational work, it is important to organize leisure for youth in individual, group, and collective forms, taking into account the social needs and requirements of youth, parents, educators, communities, the nature of the educational institution, and the spiritual and cultural interests of the regions, geographical location and demographic situation. Of course, the organizational competence of parents, educators, students and other organizations also plays an important role here.

The effectiveness of spiritual, moral and physical education of youth in the family depends on the planning, algorithmization of educational activities on the basis of a special model (Fig. 1), their 
organization on the basis of innovative methods and modern pedagogical technologies, as well as on continuous monitoring of work results.

The development of a model to strengthen the institution of the family is the logical conclusion of the theoretical analysis and justification of the conceptual foundations of the problem.

Having set this task, in our study we relied on the theoretical principles of modeling social, in particular pedagogical objects, described in the works of M.Alimova, V.G.Afanaseva, A.A.Bratko, M.Vartovfskogo, A.I.Zelichenko, V.I.Mikheeva, V.Ya.Nechaeva, Yu.K.Babanskogo, A.Yuldasheva, S.Mahmudova and others.

The term "modeling" does not yet has a single definition. Many authors understand modeling as "imitation", "reproductionn" of the studied object, its parts, feat ures in the model. 

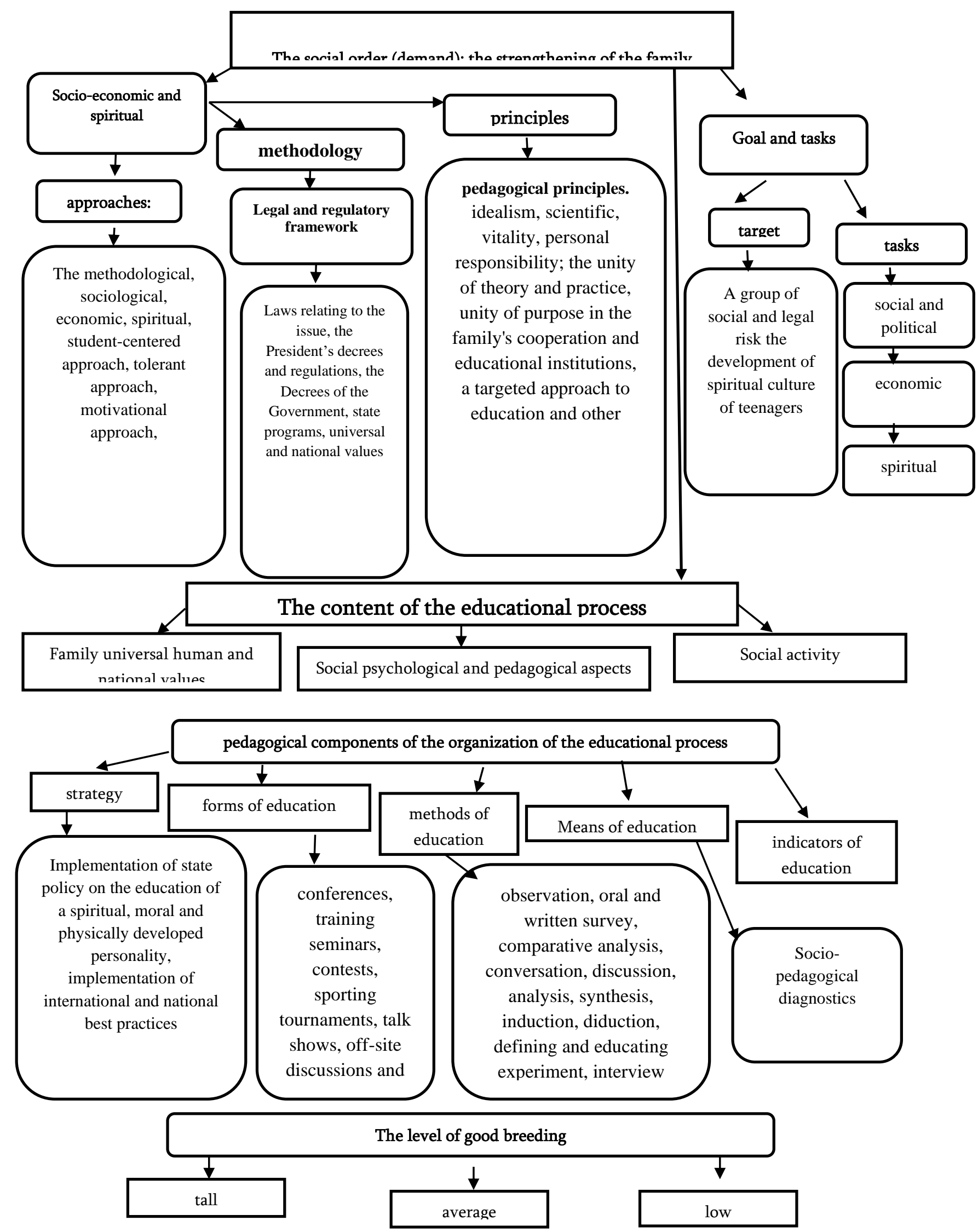

Expected result: the formation of an exemplary family in society, the formation of a spiritual, moral and physically developed personality in the family

Fig.1. Model spiritual, moral and physical development of young people in the family 
According to V.G. Afanasyev, the concept of "modeling" is used both in a wide cognitive sense and in a narrow one - as a specific way of cognition in which one system (object of research) is reproduced in another system (model) 9. P.31. The application of the modeling method in the social sciences led to the formation of a special type of scientific knowledge - "model knowledge", but which implements a heuristic function: in a special way organized cognition of an object based on its model. The model type of knowledge includes: a language for describing models; model design rules; formalized structure and functions of the model; as well as concepts for the implementation of models in practice.

A.A. Bratko defines modeling as a method of indirect cognition with the help of artificial or natural systems, capable of representing the studied object and giving new knowledge about it in certain respects. The subject of modeling can be both concrete and abstract objects, both the studied phenomena, and the phenomena to be studied (in the case of development of hypothetical models)[9. S. 45].

Model - a sign system. In a scientific study, it can take the form of circuit layout, graphics, or represent the matrix in the object system factors (structural, genetic, functional), expressed by relevant indicators. Function of the ultimate is to serve as a basis for prediction and correction activities for the future [9. P.48].

Thus, content analysis carried out by us has shown that many authors modeling is seen as "recreation", "play", "imitation" of the investigated object and its components (elements) in the model. Let us consider in detail the backbone components of our developed model for strengthening the institution of the family (Figure 1):

The main goal of family institutions is to improve the pedagogical mechanisms of education of a spiritual, moral and physically developed personality. The goal is achieved through the implementation of certain functions of family institutions.

To implement these functions, methodological aspects of strengthening family institutions are substantiated, their goals and objectives are determined, and its approaches and principles are highlighted.

At the next stage, the content of the educational process is developed, which includes the formation and development of family universal human and national values, social, psychological and pedagogical properties and characteristics, as well as the social activity of the young generation.

Next, the pedagogical components of the organization of the educational process are highlighted, which includes strategies, forms, methods and means of education that ensure the physical, spiritual, moral, and social development of the young generation.

Since the implementation of educational work is not an end in itself, but involves subsequent managerial, pedagogical and other decisions, we included components in the model that characterize the directions of decisions.

Further improvement of the work on the spiritual and moral education of youth in the cooperation of educational institutions and the family first of all requires following a number of pedagogical principles of cooperation, which include:

The content, forms and methods of raising a spiritually physically healthy generation, the choice of psychological and pedagogical conditions, factors, means from the point of view mutual cooperation; determining the direction of education, quality criteria to be formed in the individual and the organization of educational activities aimed at this;

Democratization and humanization of education of harmoniously developed generation; line forms, methods and means of education age and psychological characteristics of the individual; scientific and methodological resources to ensure the effectiveness of education of harmoniously developed generation; the unity of theory and practice in the education of harmoniously developed generation, efficient use in the educational process of the media, new information technologies;

Unity and integrity of the objectives in collaboration of educational institutions, the family and civil society institutions, differentiated approach to education; approach to education of harmoniously developed generation based on the integration of disciplines;

Organization of active leisure personality through individual, group and collective activities in the educational process; idealism, scientific, vitality, personal responsibility in the organization of educational work;

- $\quad$ The training and education of harmoniously developed generation of teaching and educational work of teachers, educators, the public is to ensure the active participation of each object;

A holistic approach to education by taking into account the social needs, the demands of family members, the interests of the territories and regions; organization of educational process in the unity of the universal and national values;

Taking account of the educational institution in the organization of educational process in continuing education, and others. 
In the spiritual and moral education of young people in the cooperation of educational institutions and the family it is advisable to widely use innovative pedagogical, communicative technologies. In particular, among them are the methods such as a continuum presentation, time-menegement, Colloquium, logical analysis, communicative activity logical situation OXY, SWOT-analysis, Case-study, educational games and other interactive forms. As well, according to the content of a joint educational activities using tools such as multimedia resources, educational and fiction literature, newspapers and magazines with special illustrations, teaching material, electronic, information and communication technologies, specific headers and reports TV and radio, social projects, popular science, art [16.P. 413-416].

In order to achieve the effectiveness of educational work plays an important role diversity of educational methods used. The most positive results provide the methods used under the purpose, content, themes and characteristics carried out educational work such as questions and answers, small group work, a story, a round table discussion, cluster, and brainstorm other.

The study of pedagogical aspects of the effectiveness of the results of spiritual and moral education of scientific, theoretical and practical nature undertaken at the spiritual, moral and physical education of young people is essential in the design of prospects for work implemented.

Thus, the study of public opinion, monitoring the results of educational work plays an important role in improving its content and in the correct choice of forms and methods of work..

To do this, it is necessary to carry out the following: development of a special diagnostic program, psychological and pedagogical study of the results of the spiritual, moral and physical development of youth; determination of the methodological basis; establishing content and principles; selection of effective methods; analysis, conclusions, a clear definition of the recommendations.

In determining the results of the upbringing of a spiritually physically healthy generation by the educational institution, family and the public, the content, forms and methods of upbringing, the real source implemented in the future may be a teacher-educator, an educational institution, women's committees and other civil society institutions, the mahalla community, members families, opinions of boys about girls, girls about guys, friends, children about parents, parents about children, adults about youth, youth about adults. (Carried out according to the study objectives, that is, the front and the integrity of detection is an aspect of education (one can study the behavior, psychological characteristics, etc. Research on the basis of a specific problem, and self-study, and so on.). When studying the level of spiritual and moral upbringing in educational institutions and in family cooperation based on goals and objectives, as well as their age and psychological characteristics, the following methods can be used: observation, oral and written questioning, comparative analysis, conversation, analysis, synthesis, induction, teaching, defining and educating experiment, interviews, mathematical and statistical analysis, retrospective research, creating a problem situation, written and oral self-esteem, assessment of others, etc. The use of this methodology of pedagogical diagnostics presents the possibility of organizing purposeful, according to a specific plan, based on the pedagogical mechanism of work carried out in order to strengthen the institution of the family, educate spiritual, moral and physically developed youth in the family.

\section{Conclusion}

Fundamental reforms carried out to form a harmoniously developed personality in Uzbekistan require further expansion of the mechanism of social partnership and public control. In particular, increasing the effectiveness of educational work carried out to form the spiritual culture of adolescents of the social risk group is also one of the important works. Studies show that in improving the effectiveness of forming the spirituality of adolescents of social and legal risk groups, it is advisable to follow the priority areas of education, pedagogical principles, pedagogical conditions and factors.

Despite the ongoing large-scale work to strengthen the institutions of the family, today there are a number of problems and disadvantages that impede the complete reform of this sphere. In particular, firstly, the legal basis for strengthening the institution of the family is not perfect; there is no solid legal basis in the field of protection and support of the family developed on the basis of studying law enforcement practice and best foreign practices in this area. Secondly, there is no effective system for coordinating and monitoring activities to strengthen the institution of the family; cooperation between the state, civil society institutions and the private sector in the development of the institution of the family is insufficient and unsatisfactory. Thirdly, the growth of family divorces is increasing, the ongoing work to prepare young people for family life is insufficient. Purposeful work to strengthen the spiritual and moral foundations of the family and traditional family values is weak. There are not enough qualified specialists dealing with the problems of strengthening the family; existing specialists have low potential. Fourth, research on various problems of family education, including the education of a spiritually and physically mature generation in the family, is conducted passively. Fifth, there is no coherent organization 
of the system activities, such as the prevention of crime in the family, training and retraining in the field of crime prevention, conflict and divorce in the family. Sixth, work is not carried out at the required level in families, educational institutions on the methodological arming of educators, parents, and the necessary skills to protect young people from different views and ideas alien to our national mentality,

Based on the foregoing, we conclude that to improve the effectiveness of spiritual, moral and physical education of young people in today's society it is necessary:

- in the content of social and humanitarian subjects taught in schools to prioritize this issue; in educational institutions appropriate to introduce special courses in areas of "Education for family life", "Psychology of family life", and the theoretical and practical laboratory "School of young family"; create for that program source;

- to create a brochure, memories, videos, online programs, materials visual propogandy (posters, leaflets, etc.) in the directions family pedagogy, family psychology, family economy, family health, the right to family demography Families, spirituality, family patterns, family business, child education in the family, the emergence of various defects in the family and their prevention, and develop a mechanism for their implementation in each family;

- in order to improve legal literacy of parents, educational institutions dealing with these issues and officials of civil society in matters of family and upbringing of the child in the family to bring to the consciousness of young people the nature and content of national and international laws by organizing in the communities, government organizations of civil registration, educational institutions cabinets, corners, "Advice for Young Families";

- in order to disseminate best practices model families, advising on matters of mutual interest relating to family problems to adjust work MOOC (massive open online sites), the online network webinar (webseminars, Web conferencing, web debates, web handling, methodological websites, etc..) To organize a special site "Secrets of family life." In this process, it becomes possible to reach a broad audience (family of different types, young people, parents of different occupations, mother-in-bride, boys and girls, professionals, and others.) For the information of their on issues of preparing young people to a healthy family life, the search for answers to their questions in this area, to expand cooperation of family, educational institutions and civil society institutions, and familiarization experiences model families;

- to be implemented in the family practice basic research on family problems show their potential on the national and international arena, methodical support on actual problems of the family institution in society, conclusions and recommendations developed on the basis of the results of experiments carried out today by modern scientific schools;

- it is advisable to introduce a method of preparation of experts in special specialization social officer to work with the families in the system of higher education;

- a need to improve the system of training and skills development of demography, sociology, family psychology and pedagogy;

- create a "Helplines" and "Universities parents", as well as training courses on preparing young people for family life;

- adaptation of the regional computer training tool (CRO) "Adolescent Health in the life cycle," prepared for the employees to strengthen health services and school teachers conducting classes on healthy lifestyle and its implementation;

- development of training and educational programs to promote healthy lifestyles, involvement of girls in physical culture and sports;

- the establishment in each enterprise, organization, mahalla, educational institutions, women's committees at all levels "Girls Clubs" to raise awareness of girls about events at home and abroad, to prepare them for active participation in social and political life of the country;

- the annual polls among the population on the theme "Family and Morality" and other issues relating to the interests of the family;

- the organization of a cycle of TV and radio programs, articles, videos and other informational and educational materials on the strengthening of the family institution, the consequences of early marriage, polygamy.

\section{References}

1. Constitution of the Republic of Uzbekistan. -Tashkent: "Uzbekistan", 2012.

2. "Family Code" of the Republic of Uzbekistan. -Tashkent: "Adolat", 1998.

3. Law of the Republic of Uzbekistan "On Family Entrepreneurship". -Tashkent: "Adolat", 2012.

4. Decree of the President of the Republic of Uzbekistan PF-4947 "On the strategy of actions for the further development of the Republic of Uzbekistan" dated February 7, 2017. (Appendix 1. Strategy of actions in five priority areas of development of the Republic of Uzbekistan in 2017 - 2021). 
5. Mirziyoyev Sh.M. Speech dedicated to the 24th anniversary of the adoption of the Constitution of the Republic of Uzbekistan: "Ensuring the rule of law and human interests is a guarantee of the country's development and the well-being of the people." Continuing our path of national development with determination, we will raise it to a new stage. - Tashkent: "Uzbekistan" NMIU, 2017, (p. 111.)

6. Mirziyoyev Sh.M. Decree of the President of the Republic of Uzbekistan PF-5325 "On measures to radically improve activities in the field of supporting women and strengthening the institution of the family" dated February 2, 2018.

7. Mirziyoyev Sh.M. Decree of the President of the Republic of Uzbekistan PF-5466 "On the state program" Youth is our future "dated June 27, 2018. "Narodnoye Slovo" newspaper, 28.06.2018.

8. Mirziyoyev Sh.M. Resolution of the President of the Republic of Uzbekistan -3907 "On measures to raise the system of spiritual, moral and physically harmonious education of young people, their education and upbringing to a qualitatively new level" dated August 14, 2018. newspaper "Narodnoye Slovo", 15.09.2018.

9. Afanasyev V.G. Modeling as a method for studying social systems. // System research. Yearbook. 1982. M .: Nauka, -S.31.

10. Spirituality: a dictionary of basic concepts. -T .: Publishing Creative House named after Gafur Gulyam, 2009. p.48,318

11. Musurmanova A. "Spirituality of the family - national pride". -Tashkent; Publishing house "Teacher", 2000, p. 200

12. Musurmanova A. Family - the support of society. -T .; Youth Publishing House, 2019.

13. Pedagogical dictionary-reference book / Author-compiled by: E.A. Seytkhalilov, B.Kh.Rakhimov, I.U.Madzhidov; under. total ed. B.Yu. Khodieva; Ministry of Higher and Secondary Special Education of RUz.-T.: "OPTIMAL LIGHT", 2011.-C 189,429

14. Convention-103 of the International Labor Organization “On maternity protection" (Geneva, 1952 June 28).

15. Convention-156 of the International Labor Organization “On Obligatory Family Workers" (Geneva, 1981 June 23).

16 Ismailova, Z., Choriev, R., Musurmanova, A., \& Aripjanova, M. (2020). Methods of training of teachers of university on advanced training courses. Journal of Critical Reviews. Innovare Academics Sciences Pvt. Ltd. P.413-416 https://doi.org/10.31838/jcr.07.05.85 